\title{
Cultivation of wheat grass and development of value added products incorporting wheat grass juice and wheat grass powder
}

\author{
S. Gautam and G. Saxena
}

\begin{abstract}
Wheat grains germinated for over a period of 2-3 days is usually called as the wheatgrass. Wheat grass being rich in various nutrients and phytochemicals makes it effective in many chronic diseases like atherosclerosis, anaemia, diabetes, thalassemia, leukaemia, breast cancer, and ulcerative colitis. The present study was conducted with an objective to cultivate wheat grass, to analyse proximate composition of wheat grass powder and chlorophyll content in fresh wheat grass and to develop value added products by incorporating wheat grass juice and wheat grass powder for cancer patients. Four commonly consumed recipes were standardized and 4 variations of each recipe were developed for cancer patients and the recipes were also evaluated for sensory characteristics. The estimated values of proximate composition of wheat grass powder per $100 \mathrm{~g}$ are $14.3 \pm 0.13$ (moisture), $4.52 \pm 0.33$ (Total ash), $1.74 \pm 0.08$ (Crude fibre), $18.55 \pm 0.195$ (Protein), 40.29 \pm 0.229 (Carbohydrate), 293.26 \pm 1.18 (Energy) and estimated value of chlorophyll in $100 \mathrm{~g}$ fresh wheat grass was found to be $484.43 \pm 12.27$.
\end{abstract}

Key Words : Wheat grass (Triticum aestivum) Juice and powder, Proximate composition, Chlorophyll, Cucumber cooler, Orange blast, Idli, Khaman

How to cite this article : Gautam, S. and Saxena, G. (2018). Cultivation of wheat grass and development of value added products incorporting wheat grass juice and wheat grass powder. Food Sci. Res. J., 9(1): 20-25, DOI : 10.15740/HAS/FSRJ/9.1/20-25. 